\title{
PROPOSTAS DE ENSINO DA HISTÓRIA E EXPECTATIVAS DE APRENDIZAGEM NA REORIENTAÇÃO CURRICULAR EM SÃO PAULO ${ }^{1}$
}

\begin{abstract}
HISTORY TEACHING PROPOSAL AND APPRENTICESHIP EXPECTANCY IN THE CURRICULAR REORIENTATION FROM SÃO PAULO
\end{abstract}

André Luiz Paulilo²

\begin{abstract}
RESUMO: O artigo discute aspectos da política curricular para o ensino de história em São Paulo. Analisa as recomendações governamentais sobre o ensino da história em escolas públicas. O autor percebe nas políticas governamentais uma orientação centralizadora nas decisões sobre diretrizes curriculares, conteúdos dos estudos e avaliações. Neste artigo procurei analisar, de um ponto de vista crítico, as representações acerca do magistério da história presente na política de reorientação curricular das secretarias de educação do Estado de São Paulo e da sua capital. No transcurso da investigação, as evidências registram um ordenamento e hierarquização da autoridade e das competências educacionais.
\end{abstract}

Palavras-chave: Ensino de história. Política curricular. Prática docente.

\begin{abstract}
The paper discusses aspects of the curricular policies to the history teach from São Paulo. The author analyses the governmental advices on teach of the history in public schools. The governmental policies seem to define a centralizing guidance, when deciding on curriculum, contents and evaluation. This paper analysis, from the critic point of view, the representations about of the history teachers present in reorientation curricular policies of the municipal and state secretariat of education from São Paulo. During the investigation, the evidences show the order and hierarchy of the authority and competences in education.
\end{abstract}

Keywords: Teach of the History. Curricular policies. Teacher practice.

\footnotetext{
${ }^{1}$ Pesquisa financiada pelo CNPq

2 Professor Doutor do Departamento de Filosofia e História da Educação da Faculdade de Educação da Universidade Estadual de Campinas
} 


\section{Introdução}

Como parte das atuais políticas de currículo e escolarização do governo de São Paulo e da Prefeitura da capital, os professores de História do ciclo II do ensino fundamental receberam uma série de materiais impressos para orientar o ensino da matéria entre 2006 e 2008. Ainda que iniciadas em gestões organizadas por José Serra, primeiro na prefeitura (2005-2006) e depois no governo do Estado (2006-2010), tratam-se de iniciativas específicas a cada uma dessas redes de ensino.

Em 2006 foi apresentado pela Diretoria de Orientação Técnica da Secretaria Municipal de Educação de São Paulo o documento geral do projeto "Ler e escrever em todas as áreas do Ciclo II". Sob o título Referencial de Expectativas para o Desenvolvimento da Competência Leitora e Escritora no Ciclo II do Ensino Fundamental, chegou aos docentes e coordenadores pedagógicos das escolas municipais da capital uma publicação institucional visando subsidiar o planejamento das ações dos professores (SÃO PAULO, 2006a, p. 7). Já sob a administração Gilberto Kassab, que em substituição ao governo Serra prosseguiu a sua política curricular, seguiram-se os referencias específicos de cada disciplina. Editado em 2006, o Referencial de Expectativas para o Desenvolvimento da Competência Leitora e Escritora no Ciclo II do Ensino Fundamental em História traz orientações de como organizar o trabalho com os diferentes gêneros de texto no ensino de História. No ano seguinte, a publicação das Orientações Curriculares para o Ensino Fundamental em História no ciclo II estabelece expectativas quanto à aprendizagem da matéria.

A mesma estratégia foi organizada na Secretaria de Estado da Educação de São Paulo em 2008 quando então os professores das escolas estaduais receberam uma versão impressa da Proposta Curricular do Estado de São Paulo para os níveis de ensino fundamental-ciclo II e médio. Embora já inicialmente discriminado por disciplina, o documento básico apresenta os princípios orientadores da proposta geral. Informa que Orientações para a Gestão do Currículo na Escola acompanham a iniciativa que, no entanto, só se completa com um conjunto de documentos dirigidos especialmente aos 
professores, os Cadernos dos Professores (SÃO PAULO, 2008, p. 9). No decorrer do ano ocorreu a distribuição desses cadernos aos docentes do ciclo II do ensino fundamental e do médio. Organizado em volumes bimestrais, todo o material dirigido ao professor constitui uma coleção de 28 cadernos por disciplina. Como as demais, a coleção de História é organizada por séries e constituída de orientações para o trabalho de sala de aula, para a avaliação e a recuperação. Em 2009, além de edições atualizadas do Caderno do Professor, a Secretaria de Estado da Educação de São Paulo também distribuiu aos alunos o Caderno do Aluno, impresso de referência para as atividades em sala de aula.

Esses esforços, que, assim, põem em evidência dispositivos de generalização de saberes e normatização de práticas, sobretudo configuram situações e modalidades de uso escolar de procedimentos pedagógicos veiculados a partir de lugares de poder determinados. Nos expedientes com que atualmente se vêm tentando determinar os conteúdos e os meios do ensino de História em São Paulo, importou-me compreender algo dos modos como veiculam representações sobre o papel da docência de história na escola pública, sobre as condições de uso das orientações curriculares por parte dos professores e sobre as relações de ensino e aprendizagem que funcionam como regras de uso dos materiais escolares. A fim de repensar as formas como o ensino de história é desse modo construído e percebido pelo poder político, analisei o conjunto de orientações curriculares editados pela secretaria municipal e estadual da educação de São Paulo para o ciclo II do ensino fundamental. Portanto, o que segue diz respeito ao estudo comparado do Referencial de Expectativas para o Desenvolvimento da Competência Leitora e Escritora no Ciclo II do Ensino FundamentalHistória, das Orientações Curriculares para o Ensino Fundamental e proposição de Expectativas de Aprendizagem-Ensino Fundamental IIHistória, da Proposta Curricular do Estado de São Paulo-História e de 16 dos seus 28 Cadernos do Professor de História e dos dispositivos materiais de sua produção e circulação. Trata-se de uma abordagem das formas e dos tipos de interação verbal a que se prestam, das representações que 
determinados agentes fazem de si próprios, de suas práticas, das práticas dos outros e da escola fundamental.

\section{As políticas de currículo e o ensino de História}

As mudanças na configuração do currículo recentemente propostas pelas secretarias de educação do município de São Paulo e do Estado afirmam as suas pretensões quanto à melhoria da qualidade do ensino das escolas públicas. São, sobretudo, respostas à situação de fracasso escolar que ambas as gestões acusam caracterizar suas redes de ensino. Em vista dos resultados obtidos nas avaliações externas ou segundo uma compreensão que considera ineficiente as políticas de descentralização que conferiram autonomia às escolas para definir seus próprios projetos pedagógicos, vem se buscando ações integradas e articuladas para reverter esse quadro. Na Secretaria de Educação do Estado de São Paulo (2008a, p.8) as iniciativas visam à produção e à divulgação de subsídios que incidam diretamente na organização da escola e das aulas. Associam-se o currículo à gestão complementando a Proposta Curricular com um segundo documento, de Orientações para a Gestão do Currículo na Escola e dirigido aos dirigentes e gestores escolares. Já as mudanças que a Secretaria Municipal de Educação propõe para o currículo do Ciclo II do Ensino Fundamental estão articuladas ao "Programa Ler e Escrever - Prioridade na Escola Municipal". Composto por três projetos - "Toda Força ao 10 Ano", "Projeto Intensivo no Ciclo I" e "Ler e Escrever em Todas as Áreas do Ciclo II" -, este programa tem a finalidade de "reverter o quadro de fracasso escolar associado à alfabetização" (SÃO PAULO, 2006a, p. 6). Em conjunto, os materiais elaborados pela Diretoria de Orientação Técnica da Secretaria Municipal orientam o ensino da leitura e da escrita em todas as séries e áreas do ensino fundamental.

A tendência a assumir que o currículo pode ser administrado por meio de uma política de orientações prevalece em ambas as propostas. Conforme sugerem Ball, Bowe e Gold (1992), os textos representam uma política 
desse tipo de diversas formas: textos legais, comentários, pronunciamentos e vídeos. Sobretudo, são produtos de múltiplas agendas e sua formulação envolve intenções e negociação dentro do Estado e do processo de formulação da política. Ball (1993) explica que assim as orientações incorporam significados e utilizam de proposições e palavras por meio das quais certas possibilidades de pensamento são construídas. Segundo sua análise, enquanto discurso, a política estabelece limites sobre o que é permitido pensar e tem o efeito de distribuir a fala, uma vez que somente algumas vozes serão investidas de autoridade. Mainardes (2006, p. 54) mostra que, com base em Foucault, Ball entende que as políticas podem então tornar-se "regimes de verdade". Em muitos sentidos, estudos como os de Ball, Bowe e Gold, como também os de Bernstein (1996), Apple (1997), Popkewitz (1997), Silva (2008) e Goodson (2008), discutem os modos como as relações de poder e dominação vão sendo institucionalizadas por meio do currículo. Não obstante as diferenças de perspectiva, suas análises evidenciam que o currículo se compõe pela construção de significados e de valores culturais, e que estes estão relacionados à dinâmica de produção do poder. Portanto, não há porque deixar de considerar as atuais pretensões de mudança nos currículos das escolas municipais da capital e das estaduais de São Paulo como um novo episódio no enredo histórico de conflitos em torno da construção e reconstrução de parâmetros para as práticas de sala de aula.

Também neste caso, trata-se de discutir como as atuais reorientações do currículo têm produzido um novo discurso regulativo e se legitimado. A política curricular que as secretarias de educação municipal e estadual de São Paulo vêm instituindo nas suas redes de ensino detalha metas e padrões de desempenho dos professores, prescreve-Ihes as estratégias e enfatiza um ensino voltado para avaliações externas. A reação contra a autonomia conferida às escolas na Lei de Diretrizes e Bases e a capacidade dos professores rejeitarem ou refratarem as mudanças de orientação assume como incontestável a suspeita dos docentes não terem tido formação adequada e da escola realçar a segregação social em termos de proficiência e rendimento dos seus alunos. Nesse sentido, os referenciais 
curriculares tanto conferem estruturação ao currículo oficial básico de toda a rede de ensino quanto contribuem para tornar gerenciáveis as performances dos docentes em sala de aula de um ponto de vista organizacional. Assim, o objetivo de organizar melhor o sistema educacional e qualificar o currículo das escolas públicas a partir de um foco definido, a atenção aos indicadores de qualidade do trabalho docente e a ambição de intervir sobre a gestão da sala de aula justificam as atuais iniciativas de reforma em São Paulo. A orientação curricular que domina o campo dessas ações é racionalista e intimamente associada a formas de administração e ao estabelecimento de metas. Nas diferentes disciplinas que compõem o currículo do ciclo II das escolas de ensino fundamental, pode-se notar que o enfoque nas práticas visa desenvolver procedimentos adequados às prescrições. Na verdade, as especificações técnicas para se lecionar a matéria apenas conservam o arcabouço estrutural que já rodeia o ensino público conquanto entesouram as disciplinas escolares como base para 0 currículo ${ }^{3}$.

Enquadrado nessa espécie de perspectiva estandardizada das atuais propostas curriculares, o ensino de História enfrenta um duplo desafio. Por um lado, demanda-se da docência em história desenvolver as capacidades de leitura e escrita dos alunos. Além das questões intrínsecas aos métodos da história e do seu ensino, os referenciais de História afirmam a necessidade do professor organizar uma rotina de leitura com os alunos e desencadear possibilidades de registro de leitura de textos de diversos gêneros. De acordo com o que mostram esses documentos, o ensino de História deve contribuir para a seleção, organização e difusão de práticas, rotinas e finalidades de leitura operada na escola por meio de estratégias capazes de estimular os estudantes a preocupar-se com a leitura e a questionar a diversidade do que é possível ler. Por outro, reinventar uma

\footnotetext{
${ }^{3}$ Segundo a perspectiva aberta por Ivor Goodson (2008, p. 28) a disciplina escolar funciona como arquétipo da divisão e da fragmentação do conhecimento na sociedade atual. De acordo com Goodson, "encapsulados no microcosmo de cada disciplina, debates mais amplos sobre os objetivos sociais do ensino são levados a cabo, mas esses debates são realizados de uma maneira insulada e segmentada (na verdade, sedimentada) na série de diferentes níveis internos e externos e nas arenas públicas e privadas do discurso.
} 
abordagem que levasse em conta as diferentes visões sobre o passado e o presente do país tem sido uma contribuição esperada por setores cada vez mais amplos da sociedade para a formação de uma nova cultura de participação. Os significados sociais da ação sobre o currículo ainda não deixam de envolver o ensino da história com a agenda política do momento. A história permanece uma disciplina central aos esforços que, no Brasil, desde o processo da abertura democrática, visam fazer 0 aluno compreender o seu tempo e perceber-se como agente social capaz de transformar a realidade. No entanto, em vez de contribuir para que o aluno adquira uma postura crítica em relação à sociedade em que vive, o ensino da história vem sendo um vetor da inclusão social. Ainda por meio do questionamento e da problematização da realidade, o ensino da história atualmente presta-se melhor à "construção de cidadãos enraizados numa comunidade de memória livremente escolhida", como percebe Dominique Borne (1998, p. 140), "sem arrogância" e "aberta a outras solidariedades que não a de nação".

Os referenciais de História hoje implantados pelo município da capital e pelo governo do Estado não são apenas marcados pelas modalidades da aprendizagem com que programam o ensino. Eles testemunham também o tipo de atenção que se dirige aos docentes dessa disciplina nas escolas públicas. O estudo da maneira como nessas instruções os especialistas e as autoridades públicas tentam se apoderar do papel que lhes convém e atribuir ao docente os papéis que escolheram para eles sugere a importância do texto na gestão da política de currículo. Nesse sentido, análises sobre o funcionamento refletido da representação, como são as de Chartier (1991) e Prost (2008), enriquecem a compreensão dos efeitos de sentido que as formas de enunciação das propostas curriculares produzem. $\mathrm{Na}$ análise do texto dos referenciais, levar em conta o conjunto dos dispositivos discursivos e materiais que constituem o aparelho formal de enunciação permite explorar os meios através dos quais a docência é percebida, construída e representada nesses documentos. Para identificar e articular as diversas relações que o poder público e os especialistas mantêm com o docente de história importa discutir as concepções de destinatários 
típicas dessas propostas curriculares. Há nos referenciais curriculares uma série de artifícios para impor uma significação unívoca, para enunciar e produzir sua correta interpretação, que é também um modo de supor o exercício adequado da docência. Por essa razão, as relações entre as atuais políticas de currículo e o ensino de história levaram-me a pensar nos discursos para e sobre os professores como um instrumento essencial para compreender as estratégias de regulação da atividade da docência nessa disciplina. Sobretudo porque as representações da docência que autoridades e especialistas afirmam ao professor fazem parte integrante da realidade do magistério, definem um campo de lutas no qual os referenciais curriculares tem uma pertinência operatória ímpar no ordenamento e na hierarquização da autoridade e das competências.

\section{A elaboração didática da História nas Orientações Curriculares}

São sérias as críticas que os estudos sobre as políticas educativas e ensino consolidaram a respeito do alcance efetivo das prescrições curriculares. Bernstein (1996), Sacristán (1998), Apple (1982) e Goodson (1995) contribuíram de diferentes formas para a abordagem da distância que há entre a produção do discurso oficial e sua incorporação pelas instituições educativas. Suas considerações acerca da passagem do discurso instrucional e regulativo para a prática insistiam que as escolas atribuem significados próprios aos dispositivos normativos oficiais. Essa perspectiva de análise contribuiu para o desenvolvimento de pesquisas preocupadas em situar o conjunto de agentes constituintes do saber escolar, especialmente professores, alunos e comunidade escolar. Especialmente Paul Willis (1991) e Stephen Ball com Ivor Goodson (1984) procuraram entender como grupos particulares atuam durante as mudanças do currículo, respondem-nas ou apropriam-se delas. A publicação no Brasil dos principais teóricos do currículo e das reflexões de Antônio Flávio Moreira (1990), André Chervel (1990), Jean Claude Forquin (1992), David Hamilton (1992), Thomas Tadeu Silva (1999) e Popkewitz (1998) consolidaram a abordagem das 
especificidades do conhecimento escolar como uma área profícua de investigação. Para Circe Bittencourt (2003, p. 13), as disciplinas escolares passaram a ser incluídas como um dos objetos importantes das investigações sobre as práticas escolares nesse processo. Os resultados mais recentes de pesquisa na área de ensino de história dão-Ihe razão. Ao mostrar o papel do professor e do seu horizonte de expectativas na construção dos significados das propostas de reforma do currículo, as análises dos paradigmas atuais do ensino de história têm permitido ver uma educação que está muito distante das intenções mandatárias. O estudo do uso efetivo do livro didático (ARAÚJO, 2001), das práticas de construção, elaboração e correção de atividades (SOARES, 2008), da apropriação dos programas de ensino (CIAMPI, 2000) e do funcionamento dos mecanismos da ação docente (CAIMI, 2008) no ensino de história vai mostrando que respostas criativas e práticas consequentes se impõem à urdidura das prescrições.

Apesar disso, a compreensão dos programas de ensino não deixa de interessar. Como avalia Monica Ribeiro da Silva (2008, p. 34-35), considerar que nas escolas se reinterpreta, reelabora e redimensiona 0 discurso oficial não significa, porém, menosprezar a relevância desse discurso. Sobretudo, sua importância está na força que exerce na produção de um novo discurso regulativo. A legitimidade que o currículo oficial confere às finalidades educacionais de escolarização das reformas quando realiza a apropriação de um ideário pedagógico já legitimado implica estudo. Nessa direção, as investigações acerca das prescrições da sua linguagem normativa (BERNSTEIN, 1996), do contexto da produção do seu texto (BALL, BOWE, GOLD, 1992) e da história da sua construção (GOODSON, 1995) constituem referências que têm permitido analisar a operacionalização da linguagem nos currículos oficiais. No Brasil, o acumulado das abordagens preocupadas com essas problemáticas adverte acerca das condições de locução daquilo que é prescrito para o ensino. Atualmente, as análises das prescrições curriculares de autores como Silva (2008), Silva (1999), Gimeno Sacristán (1998), Moreira (1997) e Silva e Moreira (1994) mostram que o apelo à noção de competências, as 
representações e as práticas que as prescrições formalizam nas escolas e a insistência na necessidade de adequação da escola às mudanças ocorridas no âmbito da economia e da cultura impactam o ordenamento das disciplinas escolares.

$\mathrm{Na}$ perspectiva aberta por esses estudos, compreende-se que as demandas políticas e sociais constituem um primeiro aspecto de reorganização dos procedimentos de ensino nas escolas públicas. Na elaboração da didática de ensino das propostas de reforma, a incorporação da agenda política de governo define encaminhamentos que dão respostas efetivas aos problemas priorizados. Assim, as atuais propostas de reorientação curricular do Governo de São Paulo e da Prefeitura da capital também contribuem para a apropriação das políticas públicas de educação nas escolas. Ainda que a fragmentação do currículo em disciplinas particularize as discussões sobre os objetivos sociais e políticos do ensino no interior de cada área do conhecimento, há expedientes visando articular e conjugar fins comuns ao ensino do que quer que seja na escola. Em muitos sentidos, o apelo às noções de competências e habilidades, a sua organização pelos ciclos e séries e a determinação dos conteúdos específicos nas propostas de ensino de História respondem a artifícios desse tipo. A prioridade para a competência da leitura e da escrita, a formação de cidadãos críticos e participantes e o compromisso com a transformação das condições de vida das crianças que frequentam as escolas públicas, que tanto as Expectativas de Aprendizagem em História quanto a Proposta Curricular de História recomendam aos seus professores, constituem o compromisso das autoridades públicas com o ensino de qualidade e tudo o que ele significa para a vulgata política do momento. Em função desse tipo de redefinição do currículo, o ensino de história incorpora todo um gênero de metodologias. As "atividades seqüenciais", as "situações de aprendizagem" e as rotinas de leitura e avaliação são exemplos de sugestões de estratégias que promovem práticas restritas, muitas vezes associadas ao trabalho de sala de aula e ao cotidiano da escola. No entanto, sob o argumento de assegurar "ações comuns" ou generalizar "padrões", definem o professor como um mediador prático das intenções de outras 
pessoas. Conforme percebeu Goodson (2008) no caso da Inglaterra, a centralização do poder de decisão nos serviços de educação significou desconsiderar o professor como intérprete moral e o definidor parcial do currículo. Igualmente, as orientações curriculares do Estado de São Paulo e da sua capital reduzem a docência às suas tarefas de mediação por meio de um repertório de procedimentos em que se insiste fazer o professor cumprir.

Outro aspecto da reorientação curricular das escolas públicas em São Paulo diz respeito aos dispositivos de sua organização enquanto proposta. A publicação e distribuição do Referencial de Expectativas e das Orientações Curriculares aos professores do ensino municipal e da Proposta Curricular do Estado e do Caderno do Professor para o magistério estadual reedita uma estratégia comum e já bem estudada de reforma do ensino ${ }^{4}$. A investigação histórica das iniciativas de organização de material impresso visando apresentar as iniciativas de mudança e modelar as práticas que então prescrevem não só tem percebido e analisado as regras que regem o uso que as reformas fazem desse tipo de material. Também vem delineando itinerários de investigação profícuos para a compreensão dos impressos de reforma como meio das representações que determinados agentes fazem de si mesmos, de suas práticas, das práticas de outros agentes, de instituições como a escola e dos processos que as constituem (cf. CARVALHO, 1998, p. 38). Nesse sentido, a ênfase na materialidade do objeto impresso, a atenção em relação à sua configuração textual e tipográfica, é uma exigência inicial da análise que se propõe aqui.

Os volumes distribuídos aos professores das escolas municipais da capital e estaduais são coloridos e ilustrados, possuem um formato de $228 \mathrm{~mm} \times 270 \mathrm{~mm}$ com lombada quadrada no primeiro caso e $198 \mathrm{~mm}$ x

\footnotetext{
${ }^{4}$ Em texto programático Marta Carvalho (1998, p. 35) tanto pensa a análise dos impressos de destinação escolar da perspectiva de sua produção e distribuição, como produto de estratégias editoriais em estrita correspondência com os usos que modelarmente Ihes são prescritos, quanto da perspectiva dos usos escolares desse tipo de impresso, abordando-o como suporte material de práticas pedagógicas na sala de aula. Catani e Bastos (1997) e Carvalho e Toledo (2007) são estudos aplicados.
} 
$258 \mathrm{~mm}$ com lombada tipo canoa no segundo ${ }^{5}$. Fundamentalmente, no entanto, as duas coleções distinguem-se pela organização do conteúdo e argumento visual. Por um lado, os três volumes de orientações da Secretaria Municipal de Educação abrangem diretrizes gerais de trabalho enquanto o material da Secretaria de Estado da Educação se constitui de fascículos bimestrais especificados por série e voltados para a resolução de situações de aprendizagem. Por outro lado, a compilação das imagens sugere algo dos projetos de realização que as secretarias Municipal e Estadual de Educação propõem. No material da Prefeitura de São Paulo prevalecem imagens do cotidiano das escolas municipais da capital. Além das ilustrações e da edição de documentos de periódicos, há fotografias de alunos e de espaços de leitura e aula das escolas do município e reproduções de trabalhos escolares dos alunos. Dos volumes produzidos pela Secretaria de Estado da Educação de São Paulo apenas consta o repertório de documentação escrita, ilustrações, fotografias e reproduções de obras de arte previstas para o uso dos professores. Comparativamente, a ideia de incorporar as experiências desenvolvidas ou vivenciadas por professores e alunos como referência de trabalho é mais acentuada no material da prefeitura que no do governo estadual, este mais voltado para a compilação de fontes e material de apoio às aulas.

Ainda de acordo com as recomendações de método dos estudos sobre a edição de textos (PROST, 1996; CHARTIER, 1991; MCKENZIE, 1986), é significativo discernir na materialidade dos impressos analisados as marcas de sua produção, circulação e uso. Não só os dispositivos do objeto tipográfico que propõem um texto a leitura produz sentido. Também as maneiras segundo as quais os textos podem ser lidos, os procedimentos de interpretação e os móveis do discurso consolidam recursos de apropriação. As condições de exercício da docência nas escolas da prefeitura e do estado, a maneira como os docentes entenderam o propósito dos impressos que receberam ou os artifícios textuais que procuram construir o leitor-professor

\footnotetext{
${ }^{5}$ À exceção do Referencial de expectativas para o desenvolvimento da competência leitora e escritora no ciclo II do ensino fundamental - história que possui lombada tipo canoa na qual se utiliza o grampeamento entre o miolo e a capa como no material distribuído pelo Governo do Estado de São Paulo em 2008.
} 
determinam modos de ler e procedimentos de interpretação significativos. Assim, tanto as representações inscritas nos textos quanto as produzidas pelos leitores importam à compreensão dos dispositivos materiais e formais pelos quais a Proposição de Expectativas de Aprendizagem em História e a Proposta Curricular de História atingem os professores. Daí, mesmo quando voltada para o "mundo do texto", a análise não pode deixar de considerar o "mundo do leitor" se pretender tratar com as peculiaridades constitutivas de um determinado gênero do discurso.

Por fim, adverte-se que os modelos inscritos em produtos culturais como as propostas curriculares remetem a práticas cujo exercício pressupõe um lugar de poder. Conforme preveniu Foucault (2008, p. 58), é preciso também descrever os lugares institucionais de onde o discurso se legitima e a situação que os sujeitos titulares da fala nesses lugares ocupam em relação aos domínios ou grupos de objetos sobre os quais falam. O fato da Proposição de Expectativas de Aprendizagem em História e da Proposta Curricular de História ser publicações institucionais das secretarias de educação do Município e do Estado circunscreve suas concepções pedagógicas às estratégias políticas do governo para os serviços de educação. Em muitos sentidos, os responsáveis pela produção dos textos desses materiais articulam os interesses mais estreitos e dogmáticos da política pública à linguagem do interesse público mais geral. Atuam de um dos diferentes lugares de produção dos textos na qualidade de especialistas e, em razão disso, "controlam" as representações sobre o como ensinar. Não só o prestígio de especialista legitima o discurso oficial, mas, sobretudo, as possibilidades de pensamento que são construídas dessa maneira investem de autoridade os responsáveis pelos textos desse tipo de impresso de orientação. À análise dos regimes de verdade que as políticas de reorientação curricular sancionam por meio das suas publicações institucionais também importa entender $o$ trabalho daqueles cuja contribuição foi instituir um discurso sobre o ensino. 


\section{O discurso competente e autoridade}

Com base em Foucault, Stephen Ball (1993) explica que a política estabelece limites sobre o que é permitido pensar e investe de autoridade somente algumas vozes. Para Ball (1993; 1994), como discurso, a política resulta de múltiplas influências e agendas e sua formulação envolve intenções e negociação dentro do Estado, num processo em que apenas algumas formulações e concepções são reconhecidas como legítimas e apenas alguns são ouvidos. Nesse mesmo sentido, as considerações de Marilena Chauí (1989, p. 7 e 147) sobre a noção de competência esclarecem que "não é qualquer um que pode dizer a qualquer outro qualquer coisa em qualquer lugar e em qualquer circunstância". A condição de prestígio daqueles que representam as regras dadas pelo mundo da burocracia e da organização permite identificar os especialistas, seus lugares na hierarquia organizacional e os meios das suas ações. Para Chauí (1989, p. 13), isso é parte do trabalho de compreensão dos artifícios mediadores e promotores de conhecimento que constrangem cada um a se submeter à linguagem do especialista. De muitos modos, essa reflexão acerca do conhecimento enquanto discurso competente contribui para o questionamento das condições de produção de materiais impressos de orientação para professores. Tanto a competência quanto a autoridade para falar e transmitir instruções aos docentes da rede de ensino são elementos que servem para intimidar. Da maneira como Elison Paim (2007, p. 162) se apropriou dessas questões, mostrou-se que "por detrás do discurso competente (...) já está dado que os professores, como os incompetentes que são, devem apenas reproduzir aquilo que é produzido por aqueles que possuem competência para tal".

Não obstante tratar-se de documentos de referência e orientação da prática docente, o Referencial de Expectativas e as Orientações Curriculares, a Proposta Curricular de História e os Cadernos do Professor de História recusam essa faceta da desigualdade entre os que pensam e os que fazem. Há um esforço das secretarias de educação do Estado de São Paulo e do município da sua capital para fazer reconhecer que o 
professorado participou na elaboração desses materiais. Nas proposições de expectativas da Secretaria Municipal de Educação de São Paulo consta a presença de um grupo de referência formado por professores em exercício nas escolas da prefeitura. Já o material publicado pela Secretaria de Educação do Estado de São Paulo (2008a, p. 8) contenta-se em anunciar que iniciou um processo de consulta a escolas e professores, para "identificar, sistematizar e divulgar boas práticas existentes nas escolas de São Paulo". Pretendendo articular conhecimento e herança pedagógicos com experiências escolares de sucesso, a Secretaria de Educação do Estado assume ter partido dos conhecimentos e das experiências práticas já acumuladas. Em ambas as secretarias, insistiram no papel do professor como co-produtor dos textos distribuídos.

Na parte específica de História da Proposta Curricular do Estado de São Paulo (2008a, p. 43) nega-se o caráter imperativo de instruções normativas a serem aplicadas à força pelos professores. O texto incentiva que o docente "siga seu próprio caminho, aplicando a seu modo, as sugestões que são oferecidas (SÃO PAULO, SEE, 2008a, p. 43). Assim, a política de produção e divulgação de subsídios que incidam diretamente na organização das aulas não parece desconsiderar o intérprete criativo que é o professor. A publicação dos diferentes volumes do Caderno do Professor História segue esse mesmo princípio, reconhecendo a possibilidade do docente realizar mudanças para adequar as propostas à sua experiência, ao seu grupo de alunos e às suas condições de trabalho (SÃO PAULO, SEE, 2008b, p. 8). Em alguns dos cadernos iniciais reconheceu-se como fundamental a intermediação do professor e a sua vivência preciosa para a realização da proposta (SÃO PAULO, SEE, 2008c, p. 45; 2008d, p. 43; 2008e, p. 54). Em muitos sentidos, o conjunto de impressos da Secretaria de Educação do Estado aceita que a proposta curricular está sujeita à interpretação e recriação.

Do mesmo modo, a Secretaria Municipal de Educação da capital acentua que as suas propostas foram produzidas coletivamente, através da reflexão de um grupo de referência da área. No Referencial de Expectativas para o desenvolvimento da competência leitora e escritora no ciclo II do 
Ensino Fundamental - História são esclarecidas as condições de elaboração do texto de orientação. Já a introdução afirma que "este texto foi elaborado com base no diálogo com professores de História das escolas e técnicos da Diretoria de Orientação Técnica (DOT) - Ensinos Fundamental e Médio, da Secretaria Municipal de Educação" (SÃO PAULO, SME, 2006a, p. 15). Os trabalhos do Grupo de Referência ${ }^{6}$, formado por professores de 10 escolas municipais, e da Equipe SME/DOT ${ }^{7}$ foram coordenados, num regime de assessoria, por Antonia Terra de Calazans Fernandes ${ }^{8}$ que cuidou da elaboração final do referencial. Ao longo do texto há 8 remissões às colaborações desses professores para as sugestões de atividades. Trataramse fundamentalmente de propostas de trabalho com diversos gêneros textuais. No documento que a Secretaria publicou depois, o Grupo de Referência modificou sua composição aumentando para 14 seus integrantes $^{9}$. A equipe técnica se estendeu de 16 para 26 integrantes também modificando a sua composição ${ }^{10}$, incluindo as equipes técnicas das

6 Constituíram o Grupo de Referência de História da Secretaria Municipal de Educação de São Paulo as professoras Angela Marques da Silva, da EMEF Dr. Manoel de Abreu, Carmem Bassi Barbosa, da EMEF Rodrigues Alves, Denise Maria Martins Pires, da EMEF Guilherme de Almeida, Ester Vieira, da EMEF Sargento Antonio Alves da Silva, Kátia Nascimento, da EMEF Antonia e Artur Begbie, Marli Oliveira de Carvalho, da EMEF Tenente José Maria P. Duarte, Olindina Francisca de O. Ferreira, da EMEF Isabel Vieira Ferreira, e Tereza Maria de Paula, da EMEF Olavo Fontoura e os professores Nilson dos Santos, da EMEF Clóvis Graciano, e Renato Trindade Júnior, da EMEF Prof. Roberto Mange.

7 A equipe da SME/DOT foi constituída por Antonio Gomes Jardim, Benedita Terezinha Rosa de Oliveira, Carlos Alberto Mendes de Lima, Delma Aparecida da Silva, Elenita Neli Beber, Ione Aparecida Cardoso Oliveira, Jarbas Mazzariello, José Alves Ferreira Neto, Lia Cristina Lotito Paraventi, Maria Virgínia Ortiz de Camargo, Rachel de Oliveira, Regina Célia Lico Suzuki, Rita de Cássio Aníbal, Romy Schinzare, Rosa Peres Soares e Tidu Kagohara.

${ }^{8}$ Possui graduação, licenciatura e mestrado em História pela Pontifícia Universidade Católica de São Paulo e doutorado em História Social pela Universidade de São Paulo. Foi professora do Departamento de História da FFLCH-USP.

${ }^{9}$ Ingressaram no Grupo de Referência de História as professoras Ana Maria Pereira, Carolina M. Marques, Denise Yurie Moraes, Márcia Maria Tripodi, Marlei Luciane Bernum e os professores Angélico dos Santos e Davi Costa Duarte. Deixaram o Grupo de Referência as professoras Tereza Maria de Paula e Kátia Nascimento e o professor Nilson dos Santos.

10 Foram responsáveis pela coordenação do processo as equipes técnicas das Coordenadorias de Educação: Adriana de Lima Ferrão, Angela Maria Ramos de Baere, Audelina Mendonça Bezerra, Clélio Souza Marcondes, Denise Bullara Martins da Silva, Elisa Mirian Katz, Eugênia Regina de carvalho Rossato, Flávia Rogéria da Silva, Francisco José Pires, Ivone de Oliveira Galindo Ferreira, Josefa 
Coordenadorias de Educação. Ainda na qualidade de assessora, Antonia Terra de Calazans Fernandes foi mais uma vez responsável pela elaboração final da proposta de História, desta vez, em conjunto com Circe Maria Fernandes Bittencourt ${ }^{11}$. As Orientações Curriculares: proposição de expectativas de aprendizagem - Ensino Fundamental II - História não referenciam as sugestões do Grupo de Referência e dão poucas pistas da sua colaboração efetiva. Comparativamente ao Referencial de Expectativas para o desenvolvimento da competência leitora e escritora no ciclo II do Ensino Fundamental, a linguagem desses dois documentos tem outra organização, adotando estratégias diferentes de persuasão do leitor.

A pluralidade de leituras e o envolvimento do docente-leitor no processo de formulação da política curricular que o material organizado pela prefeitura da capital e pelo governo do Estado entre 2006 e 2008 reconhece como fatores relevantes para a implantação das suas propostas não anulam o sistema de autoridade fundado na hierarquia funcional. A compreensão que Ball (1992, p. 22) tem da política como texto enfatiza que a sua formulação é uma questão de disputa. No caso do Referencial de Expectativas e das Orientações Curriculares de História, da Proposta Curricular de História e dos Cadernos do Professor de História, as secretarias de educação assumem a autoria dos textos definidos por especialistas responsáveis. A identificação dos elaboradores da área ou das autorias nos créditos em publicações institucionais define os lugares de procedência dos discursos reconhecidos e legitimados. A prática confirma que as publicações institucionais envolvem arranjos de função e expressam autoridade e prestígio mobilizando estratégias de legitimidade e representação. Nesse sentido, a composição dessa série de orientações

Garcia Penteado, Yukiko Kouchi, Marcos Ganzeli, Maria Antonia S. M. Facco, Maria Aparecida Luchiari, Maria Aparecida Serapião Teixeira, Maria do Carmo Ferreira Lofti, Maria Eliza Frizzarini, Maria Isabel de Souza Santos, Maria Khadiga Saleh, Sandra da Costa Lacerda, Selma Nicolau Lobão Torres, Silvia Maria Campos da Silveira, Simone Aparecida Machado, Valéria Mendes S. Mazzoli e Vera Lucia Machado Marques.

${ }^{11}$ Foi professora de Prática de Ensino de História na Faculdade de Educação da Universidade de São Paulo. Atualmente leciona no Programa de Pós-Graduação da Pontifícia Universidade Católica de São Paulo e tem participado de cursos de formação de professores da rede pública e tem-se dedicado à formação de professores indígenas. 
didáticas é tanto o resultado de uma prática de ordenação e controle dos modos de reconhecimento e veracidade dos discursos a respeito do ensino de história quanto dos arranjos de nomeação.

A abordagem de Ball acerca da política como texto considera que os professores e demais profissionais exercem um papel ativo no processo de interpretação e reinterpretação das políticas curriculares, reconhecendo que suas crenças e entendimento das propostas têm implicações para o processo de implantação das propostas de reforma. Como advertem as atuais pesquisas em lingüística e teoria literária que inspiram essas reflexões de Ball (1992), a estruturação da linguagem e as estratégias utilizadas pelos autores procuram fazer frente a essa liberdade do leitor interpretar através de uma série de recursos (BAKHTIN, 2006; BARTHES, 2002; MAINGUENEAU, 1995; ECO, 1971). Quando se considera os discursos como atos (PROST, 1996, p. 317), o sistema dos pronomes, os advérbios de circunstância, as conexões, os tempos e modos verbais permitem reconhecer na relação entre o texto e aquele que o produziu as relações entre as posições actanciais do enunciador e a do enunciatário (cf. GREIMAS; COURTÈS, 1979, p. 125). Outras estratégias actanciais (cf. FIORIN, 2008) e recursos para o autor tornar inteligível seus propósitos se dão sob a forma do gênero no qual o enunciado foi construído. Assim, a intenção discursiva do autor, sua vontade discursiva, também se revela nas estratégias linguísticas propiciadas pelo gênero do discurso escolhido.

Os referenciais curriculares são determinados por considerações técnicas e por princípios que se busca transformar em regras de ação práticas. Predominam as preocupações quanto à conduta mais adequada ou acerca da melhor opção de procedimentos para ensinar. Os esclarecimentos sobre os conteúdos da disciplina determinam o que deve ser ensinado. As longas sequências sobre os gêneros textuais ou acerca dos eixos temáticos no Referencial de Expectativas e nas Orientações Curriculares favorecem a concretização de uma possibilidade de abordagem da matéria em detrimento de outras. Nesse mesmo sentido, as explicações do conteúdo são apresentadas em função das expectativas de aprendizagem para informar o docente-leitor. Fundamentalmente, trazem soluções de 
inteligibilidade aos critérios de expressão e às problemáticas propostas no currículo. A Proposta Curricular do Estado de São Paulo repete essa mesma estrutura, embora Ihe dê outra organização. Há longas exposições sobre o conteúdo de ensino e as sequências de atividades conduzem aos objetivos do que é apresentado no currículo. Os 16 fascículos do Caderno do Professor permitem estabelecer rotinas e detalhar atividades para todo 0 conteúdo indicado para o ciclo II do ensino fundamental. Ao todo essa parte da coleção se constitui de 64 situações de aprendizagem cujo principal objetivo é a divulgação de subsídios que incidam na organização das aulas (SÃO PAULO, 2008a, p. 8). Portanto, o caráter exemplar da proposta do Estado é de outra natureza que a da prefeitura. No seu conjunto, o material procura formalizar estratégias específicas de abordagem dos conteúdos. 0 caráter prescritivo é acentuado pela preferência do modo imperativo dos verbos e a indicação minuciosa de referências bibliográficas, filmes e sítios eletrônicos adverte o leitor do repertório de recursos disponíveis para o preparo das aulas.

\section{A docência em História e as suas competências}

Um traço constitutivo das considerações técnicas e dos princípios nos referenciais curriculares é a concepção típica de destinatário que o determina como gênero. Trata-se de um tipo de enunciado voltado aos professores em exercício nas escolas públicas e, portanto, determinado pelo campo de atividade dessa coletividade de profissionais. A quem se destina o enunciado, como o que escreve percebe e representa para si os seus destinatários, qual é a força e a influência deles nos enunciados são questões das quais, para Bakhtin (2006, p. 301), dependem tanto a composição quanto o estilo de um texto. $O$ papel daqueles para quem se constrói o enunciado é excepcionalmente grande na abordagem que Bakhtin (1992; 2006) propõe. De acordo com sua compreensão, o ato de fala, inclusive o impresso, envolve uma determinada concepção de seu destinatário e da atividade humana a que se refere, projetando na obra 
uma representação de leitor. Segundo Fiorin (2008, p. 64), "o texto constrói um tipo de leitor chamado a participar de seus valores" e que, assim, "intervém indiretamente como filtro e produtor do texto". Quando nos referenciais curriculares aquele que escreveu busca orientar uma ação prática é ao seu leitor presumido - o professor - a quem se dirige. A atenção para o estudo dos dispositivos e dos mecanismos graças aos quais o texto materializa o leitor que esse autor tem em mente é particularmente fecunda para se compreender a forma como ele expressa uma representação sobre a docência. Nessa perspectiva, um levantamento sumário dos indícios linguísticos que materializam o leitor implícito nos textos desses impressos adverte que o insistente uso das formas verbais imperativas ou, então, a escolha da forma infinitiva dos verbos quando se busca orientar uma ação prática do professor não é uma mera opção estilística. (p. 18).

Entre o Referencial de Expectativas e os documentos específicos para a área de História, organizados pela prefeitura de São Paulo, há diferenças de estruturação da narrativa quanto à ênfase no que é preciso o professor fazer e naquilo que é necessário o estudante aprender. No primeiro documento, predominam as orientações de procedimento didático e o foco principal do texto é o docente. No outro conjunto, as preocupações com as práticas de aula e o método não foram abandonadas, mas as orientações para implantação das expectativas conferem centralidade ao aluno acentuando a importância das suas vivências, daquilo que ele já é capaz de fazer e daquilo que ele passa a ser capaz de perceber, identificar e construir.

O uso do modo imperativo dos verbos é uma característica marcante do Referencial de Expectativas comum às áreas do ciclo II do ensino fundamental. Sentenças do tipo "organize o registro do que os estudantes falam" (SÃO PAULO, SME, 2006a, p. 14), "formule questões que ajudem os estudantes" (SÃO PAULO, SME, 2006a, p. 26) ou "ensine-os a elaborar resumos escritos dos textos" (SÃO PAULO, SME, 2006a, p. 40) operam o sentido do fazer através de ordens que pretendem organizar a ação, descrevê-la ou prescrevê-la. No Referencial de Expectativas da área 
específica e nas Orientações Curriculares de História, predominam as formas amenizadas do imperativo e uma maior ênfase na aprendizagem do aluno. O insistente uso do verbo na sua forma infinitiva para definir a maneira mais adequada do professor proceder de fato suaviza o texto mostrando cuidado com o modo de tratar o docente-leitor. Ainda que expressões como "envolver os alunos em atividades em que a leitura seja significativa" (SÃO PAULO, SME, 2006b, p. 12), "apresentar os locais onde os alunos podem pesquisar" (SÃO PAULO, SME, 2007, p. 80) ou "organizar a análise comparativa na lousa" (SÃO PAULO, SME, 2007, p. 91) visem persuadir o docente a incorporar essas ações à sua prática, evidenciam outra opção de linguagem. Diferentemente do referencial geral do ciclo II do ensino fundamental, os documentos específicos horizontalizam a relação autor-leitor contornando algo dos protocolos de autoridade da hierarquia funcional na linguagem.

Também há nos Cadernos do Professor da Proposta Curricular do Estado um uso recorrente do modo imperativo. Como no Referencial de Expectativas comum às áreas do ciclo II do ensino fundamental, essa prática indica algo do funcionamento refletido da representação sobre a docência nas publicações institucionais. Esses textos constroem o leitordocente dizendo-Ihe o que fazer como se suspeitassem da sua escassa formação e experiência. Por um lado, trata-se de um modo usual de dar eficácia ao que foi pensado como necessário para a transmissão de conhecimentos. Entretanto, é igualmente um meio de fixar uma fórmula de trabalho. Expressões como "peça que busquem, no livro didático e em dicionários" (SÃO PAULO, SEE, 2008h, p.11) ou "oriente os alunos a sempre redigir respostas completas" (SÃO PAULO, SEE, 2008g, p. 23) e "mostre para os alunos que os documentos são a expressão do passado" (SÃO PAULO, SEE, 2008c, p. 12) visam persuadir o docente a incorporar essas ações na sua prática através de determinações. Nesses casos, o papel do docente para quem se construiu o texto ficou reduzido a de um mero executor de tarefas.

Outros modos de dizer o que é pressuposto e condição da ação docente nos manuais de ensino de história definem-se na proposta da 
metodologia, das técnicas e conhecimentos que o professor deve repassar. As atividades-modelo conduzidas nas situações de aprendizagem do Caderno do Professor e nas atividades seqüenciais das Orientações Curriculares de História visam subsidiar o docente com estratégias de abordagem da matéria. Trata-se de um expediente sistemático no primeiro documento e apenas referencial no segundo. No Caderno do Professor, as situações de aprendizagem pautam-se em número de aulas e na organização bimestral do ano letivo. Nesse formato, por exemplo, as atividades sobre o "Rio Nilo e o trabalho camponês no Egito antigo", "o código de Hamurabi", a "África, o berço da humanidade" e as "Invenções da China antiga" constituem o Caderno do Professor do $2^{\circ}$ Bimestre da $5^{a}$ série e os exercícios acerca do "Tráfico negreiro e escravismo no Brasil", da "Ocupação holandesa no Brasil", da "Mineração e vida urbana no Brasil" e da "Crise do sistema colonial" o Caderno do Professor do $4^{\circ}$ Bimestre da $6^{a}$ série. As Orientações Curriculares organizam não mais que 7 atividades sequenciais, sendo duas para o $1^{\circ}$, o $2^{\circ}$ e o $3^{\circ}$ ano do ciclo II e uma para o 40 ano. Nesse caso, o esforço vai no sentido de mostrar uma possível articulação entre as atividades e as expectativas de aprendizagem sistematizadas no documento de orientação. As diferenças de extensão e propósito de ambas as iniciativas não impedem de percebê-las como medidas para normatizar as práticas da sala de aula. À preocupação política com a qualidade do ensino e o trabalho do professor no ensino dos conteúdos respondem com um centralismo regulador que reduz as circunstâncias nas quais o professor desenvolve o seu trabalho aos fazeres mais cotidianos do exercício da docência.

Também há longas explicações sobre o conteúdo da matéria que contribuem para isso. Sobretudo o Caderno do Professor se vale dos esclarecimentos acerca da matéria de ensino como recurso para orientar o docente na condução da aula. Abordagens a respeito do "Império Romano" (SÃO PAULO, SEE, 2008f, p. 23) ou da "origem da expressão Idade Média" (SÃO PAULO, SEE, 2008c, p. 14) e da "lei de terras de 1850" (SÃO PAULO, $\mathrm{SEE}, 2008 \mathrm{i}$, p. 11) são partes de séries inteiras de discursos segundos ou derivados por cujo intermédio se outorga competência aqueles que 
puderem assimilá-los (cf. CHAUÍ, 1989, p. 12). Sob a mesma perspectiva, as considerações acerca dos gêneros de fontes principalmente realizadas no Referencial de Expectativas e nas Orientações Curriculares de História constrangem a prática do docente ao discurso do especialista. As discussões em torno do texto literário, da canção popular, do texto jornalístico, da crônica, do discurso político, das imagens e de tabelas e gráficos (cf. SÃO PAULO, SME, 2006b) orientam a organização do conhecimento e o desenvolvimento do conteúdo segundo um discurso já institucionalizado na Universidade. Igualmente assim, as recomendações quanto ao trabalho com relatos de viajantes, pinturas e fotografias (SÃO PAULO, SME, 2007) resultam desse artifício mediador e promotor de conhecimento que são as publicações institucionais de orientação curricular. $O$ atual investimento na elaboração desse tipo de discurso de vulgarização do conhecimento especializado ainda parece ser o que Chauí (1989, p. 13) identificou como a manifestação de um procedimento pelo qual "a ilusão coletiva de conhecer apenas confirma o poderio daqueles a quem a burocracia e a organização determinaram previamente como autorizados a saber".

Os boxes com orientações, as tabelas e gráficos, as legendas, os destaques e as reproduções de fontes escritas e imagens são outro conjunto de dispositivos discursivos e editoriais que constituem o aparelho formal da enunciação nos referenciais curriculares. Tanto quanto o recurso às formas verbais, esses auxílios resultam de escolhas que revelam algo das perspectivas que se tem sobre a docência. Sobretudo úteis para especificar as informações, referenciando ou detalhando dados e orientações, os boxes, as tabelas e gráficos, as legendas e os destaques constituem um intrincado sistema de indicações sobre a organização do material compilado nas propostas curriculares de história. Os protocolos de leitura que esses recursos criam não só enfatizam, evidenciam ou organizam aquilo de relevante das prescrições, como também sinalizam com procedimentos de associação entre os objetivos e os conteúdos do ensino de história, de progressão da matéria e de referenciação das escolhas. De outra parte, as reproduções de fontes escritas e imagens oferecem um conjunto de materiais para as aulas. Contribuem para subsidiar com documentos 
históricos o trabalho docente. Nesse sentido, a bibliografia, os filmes, as canções e os sítios da internet completam o repertório de indicações impressa e audiovisual considerado fundamental para o desenvolvimento da matéria de estudo. Em muitos sentidos, esses expedientes editoriais servem para suprir o professor de referências daquilo que se supõe lhe faltar ter ou saber, para atualizá-lo.

Além de discursos para os professores, os referenciais curriculares editados pelas secretarias de educação do município e do Estado de São Paulo veiculam discursos sobre os professores. Como as orientações de método e de conteúdo e o repertório indicado de materiais, as referências à docência que são feitas nesses impressos fazem reconhecer uma certa maneira de exercer o magistério. A ideia geral e comum predominante diz respeito à compreensão do docente como um mediador. Os referenciais curriculares em estudo tanto insistem que o professor assuma a sua tarefa de mediador de leitura e, assim, o papel daquele que desvela questões e problemas (SÃO PAULO, SME, 2006a, p. 08) quanto que depende da qualidade de suas mediações as competências e habilidades desenvolvidas na escola (SÃO PAULO, SEE, 2008a, p. 14; SÃO PAULO, SME, 2007, p. 22). Em atividades organizadas na forma de sequências didáticas ou projetos, através de situações de aprendizagem e das rotinas de trabalho, o professor fica responsável pela "acomodação" de um saber específico ao aluno. Principalmente, pensa-se que cumpre à docência levar em conta a realidade dos alunos, suas resistências e interesses como contrapartida da tarefa de ensinar.

A leitura do conjunto das orientações curriculares indica que há uma demanda muito variada de ações no ensino. Não escapa às secretarias de educação do Estado de São Paulo e da sua capital que estimular, orientar, valorizar, esclarecer, auxiliar e avaliar o aluno, selecionar, organizar e explicar o conteúdo ou lidar com a diversidade, questionar, solicitar, debater, problematizar e planejar o trabalho constituem referências consolidadas para o exercício do magistério. Sobretudo, as recomendações publicadas organizam e sistematizam esses procedimentos criando rotinas ou modelos de atividade para servir de referência para os docentes. Assim, 
além de ações, as orientações curriculares do Estado e do Município de São Paulo modelam sequências inteiras de aula, desde a sondagem da proficiência dos alunos até as estratégias de avaliação. Fica pressuposto nisso o domínio de uma série de habilidades e competências por parte do professor para conduzir as aulas. A opção por estratégias desse tipo de orientação do trabalho docente se não traz novas atribuições e responsabilidades ao professor parece denunciar a desconfiança que se tem da sua capacidade de pensar, definir e executar as atividades de ensino. Ainda que pensados para assegurar uma generalização de proposta, os referencias são mais uma aposta na indução imediata de ações renovadoras ou eficazes de ensino por meio da manipulação de textos normativos por parte do professorado.

Também é útil considerar as solicitações mais específicas que esses documentos veiculam. Há momentos em que os referencias curriculares apostam na criatividade do professor (SÃO PAULO, SME, 2006a, p. 35; 2006b, p. 33 e 51; SÃO PAULO, SEE, 2008a, p. 43). Recomendam que o docente crie situações de trabalho e estratégias didáticas e de leitura (SÃO PAULO, SME, 2006a; 2006b) e, por vezes, reconhecem ajustes e adaptações como tarefas criativas (SÃO PAULO, SEE, 2008c, p. 45). Invariavelmente, esse trabalho apenas se completa com o registro dos processos e resultados. As propostas de reorientação curricular insistem na necessidade de registrar o que o docente for realizando e os resultados conseguidos. Prestam-se, inclusive, a oferecer tabelas e formulários estandardizados para o preenchimento do professor (SÃO PAULO, SME, 2006a, p. 14 e 20; 2006b, p. 11; SÃO PAULO, SEE, 2008b, p. 44). Em certa medida, os referenciais curriculares associam criatividade e controle numa burocratização singular do processo educativo. Pede-se para que se registre o que os estudantes falam, como trabalham, suas expectativas, almeja-se que se planeje, execute e avalie por meio de registros sem que seja preciso pensar sobre as categorias ou modelos utilizados. Não obstante toda a preocupação com a escrituração e apesar de, por vezes, os referenciais curriculares apostarem na dimensão criativa do exercício da docência, notase neles uma cuidadosa atenção a alguns qualificativos do magistério. Em 
primeiro lugar, a responsabilidade. O Referencial de Expectativas para o Desenvolvimento da Competência Leitora e Escritora no Ciclo II do Ensino Fundamental - História realiza a articulação entre as diretrizes curriculares da Secretaria Municipal de Educação de São Paulo e a área de história assumindo que o ensino da leitura é da responsabilidade do professor de História:

Podemos partir da concepção de que a leitura é um meio de aprendizagem de conteúdos históricos e, portanto, aprender a ler e a questionar historicamente um texto deve ser encarado como objeto de ensino e aprendizagem. A leitura torna-se, assim, um conteúdo procedimental, e, com isso, é responsabilidade do professor de história planejar e desenvolver estratégias didáticas voltadas especificamente para formar leitores e para permitir que, pela leitura, os estudantes se apropriem de informações e aprendam a pensar historicamente (SÃO PAULO, SME, 2006b, p. 20).

Por outro lado, a preocupação da Secretaria de Educação do Estado de São Paulo com a gestão da sala de aula imputa ao professor a responsabilidade pelo comando do espaço da classe:

(...) ao se atribuir ao (à) professor(a) a responsabilidade pelo comando da sala de aula, não se está propondo nenhuma forma de controle autoritário, felizmente há tempos banido do ambiente escolar. Contudo, recusar o autoritarismo não significa abrir mão da responsabilidade de ensinar ou, em outras palavras, levar a aprender. Quando o(a) professor(a) se ausenta nessa relação básica, o aluno sai da escola, malformado e é nesta hora que a importância dos compromissos do docente com sua formação aparecem em toda sua dimensão. É deles que depende seu desempenho, resultante das relações com os programas oficiais, com o livro e outros recursos didático-pedagógicos, além dos alunos - que devem representar o principal objetivo de toda ação educativa (SÃO PAULO, 2008a, p. 42).

Além da responsabilidade, o compromisso e a dedicação, gostar de história e ler são atributos por meio dos quais os referenciais curriculares qualificam o trabalho do professor de História. Incluir variáveis desse tipo entre as orientações de procedimento e conduta lembra o leitor que há problemas nesse sentido e que ainda é preciso sublinhar as obrigações éticas e os valores profissionais associados à docência ao próprio docente. 


\section{A interação didática no ensino de História segundo as Orientações Curriculares}

Entre os tantos procedimentos que os referenciais curriculares adotam para orientar o professorado, o recurso ao compromisso e à dedicação dos docentes, ao gosto pela matéria que lecionam e aos seus hábitos de leitura ajuda a pensar as condições da eficácia do exercício da docência atualmente. Sobretudo, o Referencial, as Orientações, a Proposta Curricular e a série de Cadernos do Professor dão crédito aos qualificadores das interações do professor com a classe. Nessa direção, recomendam ao docente ler para a turma, debater com os estudantes, tornar possível a inclusão, apresentar os locais onde os alunos podem pesquisar, estabelecer laços entre a escola e a comunidade. Orientações no sentido de lidar com a diversidade, considerar a realidade e os interesses dos alunos e de explicitar os costumes de um bom leitor somam ainda outras indicações para a abordagem da sala de aula. Ao professor, portanto, é solicitado que propicie situações de participação dos alunos na aula, conduza-a rotineiramente e favoreça a aprendizagem ativa, baseada num convívio positivo do professor com as suas classes.

Chama a atenção nessas prescrições a maneira como são realizadas. Embora se tratando de documentos específicos da área de História, predominam orientações gerais sobre os procedimentos docentes. Pensar na organização do trabalho pedagógico ou na eficácia do ensino constitui procedimentos esperados de qualquer docente, não caracteriza uma prática específica do professor de história. O material editado pelas secretarias de educação do Estado de São Paulo e do município da capital sistematiza diretrizes para o preparo da aula, a atuação docente e a avaliação dos alunos que, comuns na rotina do magistério, insiste-se em prescrever. Em certa medida, a opção pela reiteração dos fazeres do ofício nos referenciais curriculares afirma que o ensino da história é uma especialidade da docência e, portanto, o professor que o realiza, parte dos quadros da educação. Compreender assim esse artifício dos cadernos de orientações didáticas implica reconhecer que as expectativas em relação às 
contribuições do professor de história para o ensino da leitura e da escrita ou para a gestão da sala de aula resultam mais que de uma reflexão didática específica, da política educacional do momento.

No conjunto geral, naturalmente, há recomendações especialmente dirigidas ao professor de história. Problematizar a realidade social através da análise do passado, insistindo no papel da história como iluminação do passado sobre o presente, encabeça a lista de orientações de fundo. Nessa mesma lista, recomenda-se, por exemplo, acompanhar os momentos iniciais da formação da consciência crítica, participar de maneira ativa do processo de percepção e formação dos valores constituintes da cidadania e contextualizar uma produção cultural ou documento (SÃO PAULO, SEE, 2008a, p. 41), discutir discursos políticos nas aulas e confrontar idéias do seu texto (cf. SÃO PAULO, SME, 2006b, p. 35 e 45). Orientações para o trabalho com fontes são igualmente recorrentes nos referenciais curriculares. Tem importado tratar da seleção e crítica de textos históricos de diversos gêneros (crônicas, discurso político, texto jornalístico) de imagens (mapas, obras de arte, charges, fotografia, filmes, gravuras) e representações gráficas e estatísticas com finalidades didáticas. Ciosos da solides teórico-metodológica do trabalho docente, os materiais de orientação curricular sublinham que também o ensino de história deve observar o rigor historiográfico no tratamento das fontes. Outro conjunto de recomendações que é especifica para o ensino de história diz respeito às reflexões sobre o tempo. Em relação às conexões temporais da agência humana do passado que o estudo da história produz, os referenciais curriculares basicamente orientam o docente recorrer à linha cronológica e trabalhar com diferentes concepções de tempo histórico. Sobre as temporalidades, as recomendações são tão procedimentais quanto a respeito das fontes: comparar e relacionar, criar estratégias de leitura favoráveis para a compreensão do aluno, propor projetos de trabalho, promover questões e utilizar o material didático.

Parte significativa dos referenciais curriculares estudados aqui tem a ver com o esforço de sistematizar saberes que tratam da interação professor, aluno e objeto de estudo. As formas de conduzir a classe e o 
controle da sua disciplina, os gestos, as maneiras de fazer e os procedimentos de conduta entre outras tantas ações implícitas da aula são assumidas como diretrizes. Parece ser central às atuais propostas de reorientação curricular da cidade e do Estado de São Paulo promover estratégias de abordagem da classe e de condução das atividades. Ainda que presentes, as recomendações acerca do trabalho com diferentes linguagens, com fontes e recursos audiovisuais, por meio de dramatizações e de jogos e de organização de eventos, debates e passeios secundam a preocupação com a rotina dos fazeres escolares. Esses referenciais curriculares contemplam indicações do que anotar na lousa, de quando é preciso passar entre os grupos, sobre a conveniência de se corrigir a lição de casa e da utilidade de toda uma série de outras medidas relacionadas à sala de aula. Assim, mais até que os métodos de trabalho do professor de história, o Referencial de Expectativas da Prefeitura e a Proposta Curricular de História do Estado focam a aptidão do magistério para lecionar.

Para ministrar aulas, conta-se que esses recursos sejam perspicazes para efetivar relações de ensino e aprendizagem de cada conteúdo para cada faixa etária. Essa concepção da atuação docente na sala de aula sugere que a persuasão do aluno estará garantida se considerada as suas fases de vida e condições sociais. A falta de saber do aluno ou a sua má vontade, que podem ser muito difíceis de persuadir, jamais são designadas. Ao professor de história, afirma-se que as vivências escolares dos alunos, o entendimento das dimensões históricas das vivências deles e o domínio de conteúdos relacionados aos problemas vividos por eles fundamentam o objeto do seu trabalho que é a aprendizagem desses alunos (SÃO PAULO, SME, 2007; SÃO PAULO, SEE, 2008a). Os pontos que então merecem ser enfatizados dizem respeito ao compromisso dos alunos com suas ações. Nos referenciais insiste-se que fazer os alunos produzirem, providenciarem, trocarem informações ou questionarem, entre tantos outros procedimentos de aprendizagem, depende do tipo de trabalho realizado na escola. No entanto, essas atitudes não são a expressão imediata, automática e objetiva das estratégias de persuasão que se recomendam aos professores nos referenciais curriculares. Servir de exemplo ou considerar a realidade 
dos alunos e seus interesses não garante eficácia plena aos modos do professor viabilizar a aprendizagem escolar. Essas convenções que visam a fazer o professor motivar o aluno com práticas compreensíveis $e$ significativas apóiam-se em valores da época: o atrativo das fontes, a facilidade do que está pronto para consumir, o sucesso certo e instantâneo que gratifica. Ocorre que o desejo de que todos os alunos vivam, diariamente, a experiência de ser capazes de compreender as instruções, de aplicá-las de fazer progressos comporta risco autêntico nas turmas em que a maior parte deles vem de famílias distanciadas da cultura escolar. Conforme sugerem os estudos de Fonseca (2006, p. 70), Caimi (2008, p. 184-185) e Rocha (2009, p. 221) muitos professores diminuem sensivelmente 0 nível das exigências perante as dificuldades que suas turmas apresentam. Nesses casos, as atividades que dão segurança, como as tarefas de execução parcelada e rotineira, são privilegiadas. Por outro lado, quando convencido que os horizontes de experiência dos seus alunos são limitados ao meio urbano imediato, o professor prefere não abordar experiências ou realidades culturais que Ihes são muito estranhas (SAVIANI, 1991, p. 74-75).

A mirada que os referenciais curriculares lançam sobre as condições da eficácia do exercício da docência abrange também considerações sobre a escola. Nesse ponto, há singularidades de entendimento que se difíceis de articular num mesmo conjunto de considerações, permitem especificar tendências importantes de enquadramento institucional do magistério. No Referencial de expectativas para o desenvolvimento da competência leitora e escritora no ciclo II do ensino fundamental, o docente é posto a serviço da investigação e sondagem das características do letramento da comunidade a que pertence a escola. Junto à equipe técnica e outros funcionários e estudantes, o professor deve contribuir com o processo de avaliação diagnóstica dos alunos que inclui a elaboração de estratégias para verificar o grau de proficiência de leitura em diversas esferas discursivas. Já o Referencial de expectativas para o desenvolvimento da competência leitora e escritora no ciclo II do ensino fundamental-História limita-se a afirmar que o desenvolvimento da competência leitora e escritora é 
responsabilidade de toda a escola. Oferece instrumentos de organização do trabalho a ser realizado tendo em vista subsidiar as ações desencadeadas pelo Projeto "Ler e Escrever em todas as áreas do Ciclo II", mas apenas trata do ensino de História. Essa concepção volta nas Orientações curriculares: proposição de expectativas de aprendizagem - Ensino Fundamental II - História que, no entanto, avança no sentido de reconhecer que todos os sujeitos que participam da escola, de algum modo, interferem e constroem o saber escolar. Assim, chama a atenção para o fato de além de alunos e professores e demais educadores da escola, os pais, editores e autores de livros didáticos e autores de referência da historiografia contribuem para as escolhas do que se espera ensinar e do que se aprende realmente de história na escola (SÃO PAULO, SME, 2007, p. 32). Enfim, na Proposta Curricular do Estado de São Paulo a escola é vista a partir da sua estruturação funcional e o professor do seu lugar nessa organização. A fim de que todos se apropriem das suas orientações, o documento insiste que a escola deve fazê-lo coletivamente, "tendo à frente seus gestores para capacitar os professores em seu dia-a-dia" (SÃO PAULO, SEE, 2008a, p. 15).

Entre a percepção das formas de manifestação dos saberes históricos e a concepção de que são administráveis, os referenciais curriculares testemunham que as estratégias de constituição do conhecimento e das aprendizagens em história são tão plurais quanto as próprias discussões teórico-metodológicas e historiográficas. Organizados em previsão e controle, resta saber se quando defronte aos professores suas informações são diretamente utilizáveis, seus protocolos de ação respeitados e suas "receitas" capazes de nutrir a troca de experiências. É perguntar sobre o que as propostas de reorientação curricular incorporam às práticas de ensino perante as praxes do processo de trabalho dos professores. Aos formuladores das atuais propostas curriculares, não ocorreu reconhecer que a eficácia dos referenciais depende da percepção e do julgamento de seus destinatários. No entanto, quantas vezes o engodo e a ostentação do aparato das secretarias de educação que o exercício da docência desmente 
não são vistos como ineficiência, incompetência ou incapacidade do professor?

\section{Referências Bibliográficas}

APPLE, M. Conhecimento oficial: a educação democrática numa era conservadora. Petrópolis: Vozes. 1997. Ideologia e currículo. São Paulo: Brasiliense. 1982.

ARAúJO, L.T. O uso do livro didático no ensino de história: depoimentos de professores de escolas estaduais de ensino fundamental situadas em São Paulo. São Paulo, 2001. Dissertação (Mestrado) - Programa de Estudos Pós-Graduados em Educação: História, Política, Sociedade da PUC-SP. 2001.

BAKHTIN, M. Estética da criação verbal. São Paulo: Marins Fontes. 2006. . Marxismo e filosofia da linguagem: problemas fundamentais do método sociológico na ciência da linguagem. 6 ed. São Paulo. 1992.

BALL, S. Educational reform: a critical and post-structural approach. Buckingham: Open University Press. 1994. . What is policy? Texts, trajectories and toolboxes. Discourse, Londres, v. 13, n. 2, p.10-17. 1993.

BALL, S.; BOWE, R.; GOLD, A. Reforming education \& changing schools: case studies in policy sociology. Londres: Routledge. 1992.

BALL, S.; GOODSON, I. Defining the curriculum: histories and etnographies. Londres: Falmer Press. 1984.

BARTHES, R. O prazer do texto. 3 ed. São Paulo: Perspectiva. 2002.

BERNSTEIN, B. Classes, códigos e controle. A estruturação do discurso pedagógico. Petrópolis: Vozes. 1996.

BITTENCOURT, C. Disciplinas escolares: história e pesquisa. In: OLIVEIRA, M. A. T.; RANZI, S. M. F. (Org.). História das disciplinas escolares no Brasil: contribuições para o debate. Bragança Paulista: EDUSF, p. 9-38. 2003

BORNE, D. Comunidade de memória e rigor crítico. In.: BOUTIER, J; JULIA, D. (Org.). Passados recompostos: campos e canteiros da História. Rio de Janeiro: UFRJ; FGV, p.133-141. 1998.

CAIMI, F. E. Aprendendo a ser professor de história. Passo Fundo: Editora UPF. 2008. 
CARVALHO, M.M.C. Por uma história cultural dos saberes pedagógicos. In: SOUSA, C. P.; CATANI, D. B. (Org.). Práticas educativas, culturas escolares, profissão docente. São Paulo: Escrituras Editora. 1998.

CHARTIER, R. O mundo como representação. Estudos Avançados, 11 (5), p. 173-191. 1991.

CHAUÍ, M. Cultura e democracia. São Paulo: Cortez. 1989.

CHERVEL, A. História das disciplinas escolares: reflexões sobre um campo de pesquisa. Teoria \& Educação. n. 2, p. 177-229. 1990.

CIAMPI, H. A história pensada e ensinada: da geração das certezas à geração das incertezas. São Paulo: EDUC. 2000.

ECO, U. Obra aberta. São Paulo: Perspectiva. 1971.

FIORIN, J. L. As astúcias da enunciação: as categorias de pessoa, espaço e tempo. 2 ed. São Paulo: Ática. 2008

FONSECA, T. N. L. História e ensino de história. 2 ed. Belo Horizonte:

Autêntica. 2006.

FORQUIN, J-C. Saberes escolares, imperativos didáticos e dinâmicas sociais. Teoria \& Educação. n. 5, p. 28-49. 1992.

FOUCAULT, M. A arqueologia do saber. $7^{a}$ edição. Rio de Janeiro: Forense Universitária. 2008

GIMENO SACRISTÁN, J. O currículo: uma reflexão sobre a prática. $3^{a}$ edição. Porto Alegre: Artes Médicas. 1998.

GOODSON, I. F. Currículo: teoria e história. Petrópolis-RJ: Vozes. 1995. 2008. . As políticas de currículo e de escolarização. São Paulo: Vozes.

GREIMAS, A. J.; COURTÈS, J. Sémiotique: dictionnaire raisonné de la théorie du langage. v. 1, Paris: Hachette. 1979.

HAMILTON, D. Sobre as origens dos termos classe e curriculum. Teoria e Educação, Porto Alegre, n. 6, p. 33-52. 1992.

MAINARDES, J. Abordagem do ciclo de políticas: uma contribuição para a análise de políticas educacionais. Educação e Sociedade, Campinas, v. 27, n. 94, p. 47-69, jan./abr. 2006.

MAINGUENEAU, D. O contexto da obra literária. São Paulo: Martins Fontes. 1995.

McKENZIE, D. F. Bibliography sociology os texts: panizzi lectures. Londres: The British Library. 1986.

MOREIRA, A. F. Currículo: questões atuais. Campinas: Papirus. 1987. Currículos e programas no Brasil. Campinas: Papirus. 1990.

PAIM, E. A. Do formar ao fazer-se professor. In: MONTEIRO, A. M.; GASPARELLO, A. M.; MAGALHÃES, M. S. (Org.). Ensino de história: sujeitos, saberes e práticas. Rio de janeiro: Mauad X, p. 157-171. 2007. 
POPKEWITZ, T. História do currículo, regulação social e poder. In: SILVA, T. T. (Org.). O sujeito da educação: estudos foucaultianos. Petrópolis: Vozes, p. 173-210. 1998.

Reforma educacional: uma política sociológica. Poder e conhecimento em educação. Porto Alegre: Artes Médicas. (1997)

PROST, A. As palavras. In: RÉMOND, R. (Org.). Por uma história política. Rio de Janeiro: FGV Editora, p. 295-330. 1996.

Doze lições sobre a história. Belo Horizonte: Autêntica. 2008.

ROCHA, E. A. B. Livros didáticos de história: diversidade de leitores e de usos. In: ROCHA, E. A. B.; REZNIK, L; MAGALHÃES, M. S. (orgs.). A história na escola: autores, livros e leituras. Rio de Janeiro: FGV editora, p. 201226. 2009.

SÃO PAULO (Cidade). Referencial de expectativas para o desenvolvimento da competência leitora e escritora no ciclo II do ensino fundamental. São Paulo: SME/DOT. 2006a.

Referencial de expectativas para o desenvolvimento da competência leitora e escritora no ciclo II: caderno de orientação didática de História. São Paulo: SME/DOT. 2006b.

Orientações curriculares e proposição de expectativas de aprendizagem para o ensino fundamental: ciclo II - História. São Paulo: SME/DOT. 2007.

SÃO PAULO (Estado). Proposta Curricular do Estado de São Paulo: História. São Paulo: SEE. 2008a.

. Caderno do Professor. História: ensino fundamental. $5^{a}$ série $-1^{0}$ bimestre. São Paulo: SEE. 2006b.

- Caderno do Professor. História: ensino fundamental. 6a série - $1^{0}$ bimestre. São Paulo: SEE. 2008c.

. Caderno do Professor. História: ensino fundamental. $7^{a}$ série $-1^{0}$ bimestre. São Paulo: SEE. 2008d.

Caderno do Professor. História: ensino fundamental. $8^{a}$ série $-1^{0}$ bimestre. São Paulo: SEE. 2008e.

Caderno do Professor. História: ensino fundamental. $5^{a}$ série - $3^{0}$ bimestre. São Paulo: SEE. $2008 f$.

Caderno do Professor. História: ensino fundamental. $7^{a}$ série $-3^{\circ}$ bimestre. São Paulo: SEE. 2008g.

. Caderno do Professor. História: ensino fundamental. $5^{a}$ série $-4^{0}$ bimestre. São Paulo: SEE. 2008h.

. Caderno do Professor. História: ensino fundamental. $7^{a}$ série $-4^{0}$ bimestre. São Paulo: SEE. 2008i.

SAVIANI, D. Escola e democracia. 25 ed. São Paulo: Cortez; Autores Associados. 1991. 
SILVA, M. R. Currículo e competências: a formação administrada. São Paulo: Cortez. 2008.

SILVA, T. T. O currículo como fetiche: a poética e a política do texto curricular. Belo Horizonte: Autêntica. 1999.

SILVA, T. T.; MOREIRA, A. F. (Org.). Currículo, cultura e sociedade. São Paulo: Cortez. 1994.

SOARES, O. P. A atividade de ensino de história: processo de formação de professores e alunos. Araraquara: Junqueira \& Marin. 2008.

WILLIS, P. Aprendendo a ser trabalhador: escola, resistência e reprodução. Porto Alegre: Artes Médicas. 1991.

Recebido em 19 de outubro de 2012. Aprovado em 08 de dezembro de 2012. 